\title{
TRADITION AND MODERNISM IN YORUBA ARCHITECTURE: Bridging the Chasm
}

\section{Olusola A. Sonaiya \& Ozgur Dincyurek}

\begin{abstract}
Vernacular and modern architecture have mostly been seen as antitheses, impossible to reconcile, especially in Africa. They appear to belong to different ages, utilize different materials and methods, and encourage or support different lifestyles. This paper aims at seeking points where a merging of principles may be attempted between the two positions.

The study is based on a survey on the traditional architecture of the Yoruba people of West Africa. The decline in popular use of this building tradition and its rejection by design practitioners raises some physical and psychological issues which are examined in this paper. These include: spatial layout, use and quality, ecology and economy, concepts, meaning and perception. The fate of Yoruba traditional built culture depends on a conscious attempt to reconcile it with people's contemporary needs, lifestyles and world views.

Therefore, a brief introduction on the importance of Yoruba architecture and its preservation will be followed by a general definition of its features and characteristics, advantages and disadvantages. Finally, the problems posed by the architecture's modern trends in Yoruba land will be examined. It is hoped that such works may assist in the development of a truly responsive and sustainable architecture for the Yoruba people. The proposed solutions may be applied in other parts of Africa, or in regions with similar cultural or geographical concerns.
\end{abstract}

Keywords: Traditional Architecture, Yoruba Culture, Sustainability, Inadequacies of Modernism, Appropriate Design.

\section{INTRODUCTION}

Although recent years have seen increasing interest in vernacular architecture, its advantages are still to be fully recognised and utilized in contemporary design. Oliver (2007) states that unless the resources of traditional architecture are tapped, there is no way to cope with the problems of urban housing, especially in developing countries. However, more recently, design theorists are conducting research in the field of vernacular architecture, especially where it concerns social and cultural appropriateness (Ahmed, 2003). This article deals with the Yoruba people of south west Nigeria and their traditional architecture.

The Yoruba people lay claim to an ancient heritage. Their language is believed to have separated from their closest neighbours more than 3,000 years ago. There is evidence that their most powerful empire, the Oyo Empire, was on the ascendant in the second century AD (Mclntosh and Mclntosh, 1986). Their art works and music are highly admired throughout the western world and the former are on display in many museums. However, their architecture has been relatively underemphasized, and this may be due to a num- 74 ber of reasons. The natural materials of which they built are easily destroyed, especially in a humid climate of torrential rains such as the West African rainforest region. The relative lack of monumental architecture among the Yoruba led many researchers to ignore their building traditions altogether. Furthermore, the perception of their dwellings by the Yoruba people themselves was one of impermanence, and they frequently allowed unused rooms or houses to fall to ruin if no family member was present or eligible to take them over. Moreover, the popular bias against unbaked earth habitations may have discouraged serious academic interest in Yoruba architecture in the past (Elleh, 1997).

Nevertheless, the Yoruba people do have their own distinctive dwellings, which they developed to suit their lifestyles and to which they tenaciously clung during their years of slavery in the sixteenth to nineteenth centuries. Researchers such as Vlach (1984, 1986) and Osasona (2001, 2005) have studied Yoruba architecture and identified four major types. Recent findings have identified one further type, the Front Hall type, and a sub-type called the Multiple Unit type (Sonaiya, 2008). Moreover, the shotgun house so popular in the American 

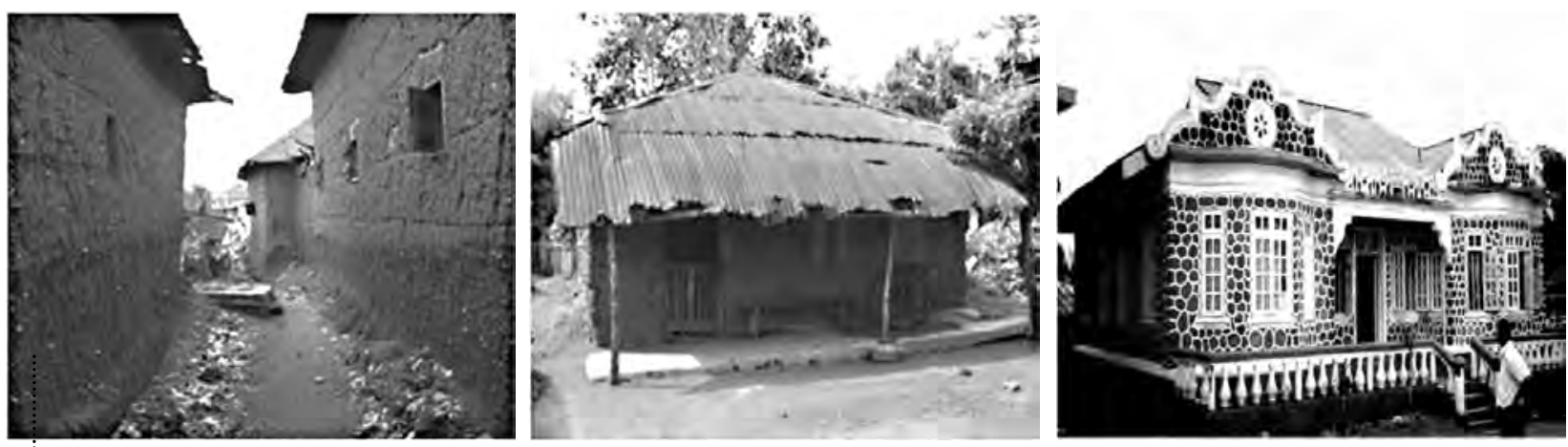

Figure 1. A Yoruba neighbourhood, a Row house with hall, and an Afro-Brazilian bungalow

south has been traced to Yoruba unit and row type houses (Vlach, 1984). The building tradition in their native Nigeria has evolved and developed many species of the genus 'Yoruba house'.

Modernism came to Africa by means of European missionaries and slave traders, and it has left an indelible mark on the built environment of the Yoruba. It has been noted that the concept of àsà or tradition in art and architecture embodies the need for change, initiative and creativity (Filani, 2003). A people quick to embrace novelty, the Yoruba first incorporated the lifestyles and built forms of the colonialists into their traditional structure, which then began to be replaced by them. The skylines of modern Yoruba cities, if indeed they may still be called such, are becoming indistinguishable from those of any other city in the world. Educated Nigerians have learned to despise their own built heritage for its materials, form and connotations, while the basic advantages which it possesses have been largely overlooked (Okoye, 2002). These issues will be examined in the following paragraphs.

\section{YORUBA ARCHITECTURE'}

The architecture of the Yoruba people is both unique and, to an extent, similar to that of their neighbours on the West African Coast. The high level of urbanization displayed by the Yoruba people is largely the cause of their architectural complexity. The people live in urban centres, but work in the primary and secondary farmlands surrounding their towns, called oko etile and oko egan respectively (Bray, 1968). Due to this situation, it was possible for them to develop both an urban house type which is the courtyard house as well as rural houses.
All the house types recognizably belong to a single family of floor plans and a single building tradition. This may be seen by the two-room module known as the Unit type, called the basic Yoruba house form (Asojo, 2003). It consists of $3 \times 3 \mathrm{~m}$ rooms, one being for public, and the other for private use. In cases where this two-room arrangement breaks down as in some row or courtyard houses, the sizes remain the same, and the functions are usually retained.

The slave trade which lasted between the sixteenth and nineteenth centuries was responsible for the Brazilian influence on Yoruba architecture. A house type called the Sobrado was brought back by the repatriated Yoruba slaves, which they adapted to fit their own traditional two-room module and spatial divisions (Vlach, 1984). This resulted in the Afro-Brazilian or Modern Yoruba Bungalow. A new house type also developed on the shores of Africa, seemingly with no external influence, the Front Hall type (Sonaiya, 2008). A classification of all the

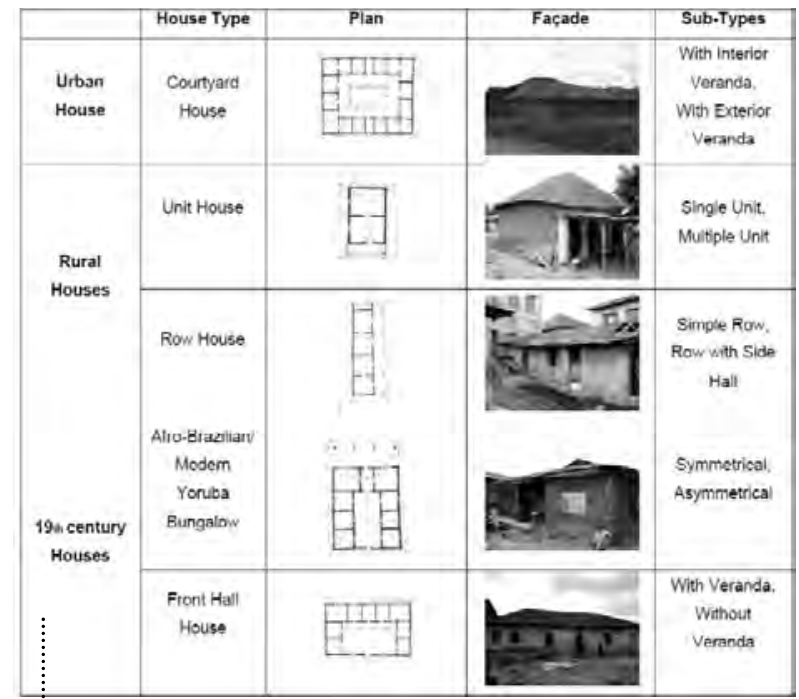

Table 7. Classification of Traditional Yoruba house types ( Sonaiya, 2008)

1 The information in this section first appears in Sonaiya, O.A. (2008) Evolution, Analysis and Future of the Traditional Yoruba House, Masters Thesis, Eastern Mediterranean University, TRNC. 

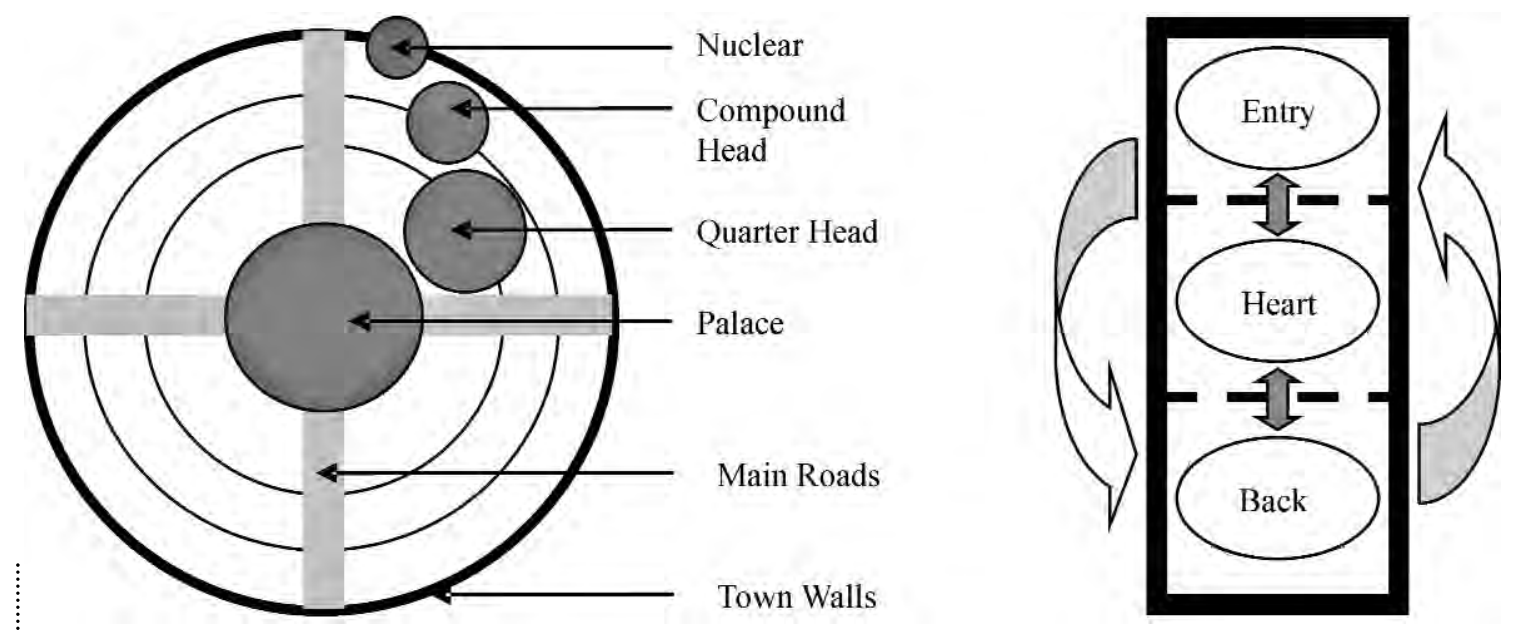

Figure 2. (a) Spatial arrangement of Traditional Yoruba Town, and (b) Traditional Yoruba House (Sonaiya, 2008)

known traditional Yoruba house types and subtypes is given below (See Table 1).

The method of construction is also common to all of the house types. Although the wattle-anddaub technique was originally used, hand-moulded earth courses later replaced it in traditional Yoruba houses. The spatial layout unique to these traditional dwellings is unaltered in all the house types as well. This is because town and house form and arrangement were not randomly arrived at, nor were they merely the result of climate concerns, construction methods or convenience.

Urban Spatial Layout: The traditional Yoruba town was walled and hierarchically arranged in concentric circles (Fig. 2a). Palace, shrine and market place occupied the centre, while dwellings were arranged around these in order of importance of the owners (Afolabi Ojo, 1966). The physical structure of the town incorporated the cone, which yields a circle in two dimensions, and a cross created by the intersecting main roads. Both the cone and the number four (4), and by extension four sided shapes such as squares and crosses, were symbolically significant to the Yoruba (Babalola, 2001). The cone symbolizes 'ori' which means 'head' or 'personal destiny'. The crowns of Yoruba kings are therefore cone shaped, as is a ritual leather object which every Yoruba adult possessed in the past (Lawal, 2000). The square symbolizes 'iwa' which means 'to be' or 'human behaviour'. Both of these ideals were considered to be of utmost importance to the Yoruba (Idowu, 2005) and the juxtaposition of these two symbolic forms was intended to encompass all of human life; secular and sacred, economic, political and religious.

$-76$
The urban dwellings built by the Yoruba people were quadrangular and arranged around an open courtyard. The visual and physical proximity of neighbours in this house type may have encouraged neighbourliness and good behaviour (iwa) expressed by the choice of four angled forms.

The dwelling unit is also seen to be divided into three zones: the entry, the heart and the back (Sonaiya, 2008) (Fig. 2b). These zones do not necessarily correspond to open, semi-open and closed spaces, nor to private, semi -public and public areas (Table 2). They occur in all traditional house types and consist of the same basic spaces:

- Entry: front yard, veranda, entry corridor, parlour(s)

- Heart: courtyard, hall or day room, sleeping rooms

- Back: backyard, conveniences, kitchen, store

Space Use: Each one of these spaces was used for specific activities by different age and gender groups at different periods of the day. As has been found to be the case in rural Mediterranean Courtyard houses, most of life was concentrated in the open and semi-open spaces of the dwelling (Dincyurek et al, 2007). The front yard, veranda and courtyard are used for entertaining guests, recreation and other social activities, while the back yard is used for cooking and locating the conve-

\begin{tabular}{|c|c|c|c|}
\hline & Private & Semi.Public & Pubilic \\
\hline Open & Converiences & $\begin{array}{c}\text { Courtyard Backyard (ine } \\
\text { Kitehon) }\end{array}$ & Fetorly Yard \\
\hline $\begin{array}{l}\text { Semi- } \\
\text { Open }\end{array}$ & & Veronda & \\
\hline Ėlosed & Slesping Rooms, Parlour, Store & Day Rromv' Hall & $\begin{array}{l}\text { Entry } \\
\text { Comidor }\end{array}$ \\
\hline
\end{tabular}

Table 2. Spaces in Traditional Yoruba Houses 

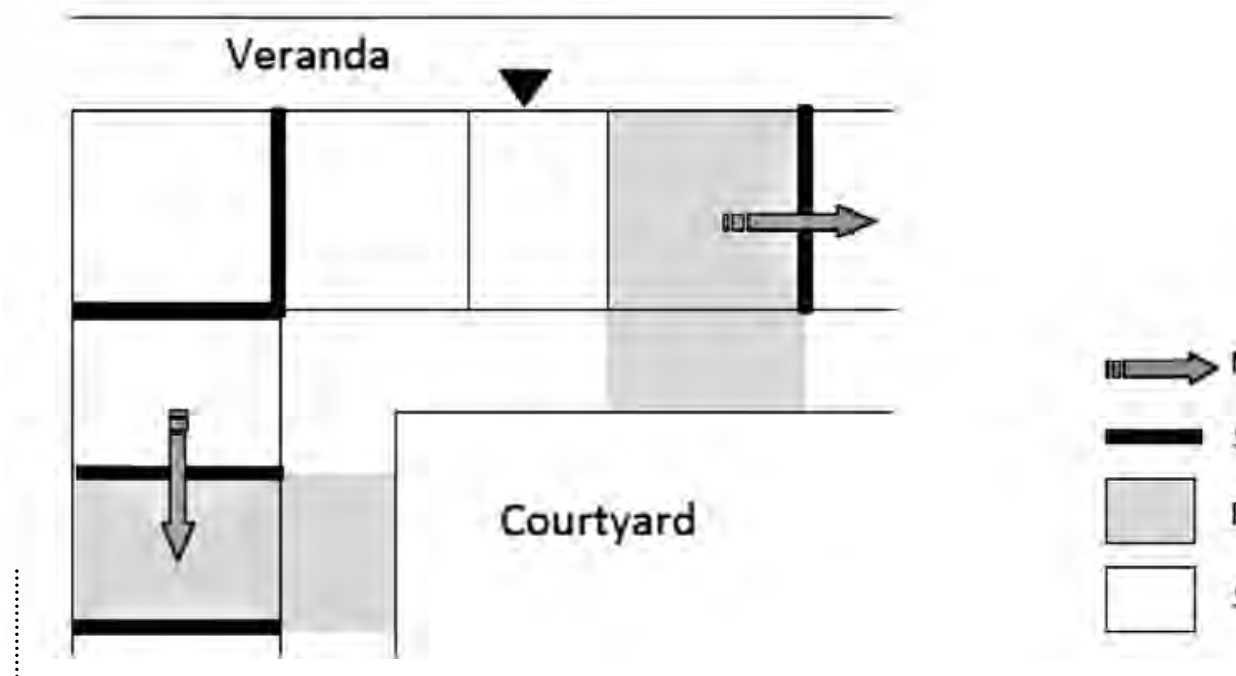

Noise Travel

Shared Walls

Perceived Territory

Shared (un-owned) space

Figure 3. Territoriality and Space Sharing in a Courtyard House

niences.

The notable exception is the hall with its entry corridor, which is a closed space, but very frequently used. It may be seen as a closed courtyard. Located in the heart of the home, it functions both as a circulation space to the parlours and sleeping rooms and as a social gathering space. This therefore provides a greater measure of privacy and security than the veranda for small children and the aged. Despite often lacking window openings, the hall is thermally comfortable due to its thick earthen walls and high roof which allows hot air to rise and escape, leaving the interior cool. The front and rear doors are also often kept open to facilitate a cross breeze across the space.

\section{ISSUES AFFECTING THE CONTINUITY OF THE TRADITIONAL YORUBA HOUSE}

Its attractive features notwithstanding, traditional Yoruba architecture is being increasingly abandoned by the Yoruba people and ignored by design professionals. This is partly due to a number of disadvantages that it possesses, enumerated below. While some of these are intrinsic to the materials or building techniques of the time, others may be rectified.

\section{Disadvantages}

- Lack of Privacy: The courtyard plan has minimal privacy due to the fact that rooms share at least two walls with neighbours. The courtyard itself is also common property (See Fig. 3).

- Image and Functional Obsolescence:
Unbaked earth habitations are commonly looked down upon by literate members of the society, and therefore undesirable aesthetically. The lack of interior conveniences, plumbing, etc., also makes this house type undesirable to modern users.

- Undefined Territoriality: It is often difficult to ascertain who has rights and responsibilities for shared spaces and amenities (Fig. 3). The situation is aggravated by situations in which nonrelatives cohabit. The resulting lack of maintenance is also a financial and social problem showing a growing lack of community spirit.

- Sharing of Spaces: Conveniences, kitchens, courtyards, etc., must be used communally in such houses, which is usually unsatisfactory to the residents.

- Structural Failures: Inappropriate earth building techniques for the foundations result in severe structural failures and slumping of exterior walls due to erosion in the humid climate of Nigeria.

Nevertheless, there are significant advantages offered by the Yoruba house, which should be harnessed. These are especially important considering the present concerns about global health and sustainability as well as growing socio-cultural problems including lack of a living quality and legibility in urban environments and a 'loss of place'. Particular advantages are enumerated below.

\section{Advantages}

- Ecology: The timber and earth of which traditional Yoruba dwellings are customarily built have very important benefits for the environ- 
ment such as low pollution, low energy costs and climate- modification. Natural materials are also seen to be sustainable and renewable, (Day, 2002; Dayartne, 2003; Meir, 2006) with a further advantage of easy and safe demolition.

- Economy: Elleh (1997) has observed that Africa is building beyond its technology and resources. The ubiquity of the material and the low skill level required in order to use it in construction make earth the most economically viable form of building. The compound house form itself has been found to possess economic advantages due to its efficient use of land, sharing of resources, suitability for high-density housing, etc., (Andersen et al, 2006). Furthermore, the courtyard arrangement allows for adequate natural ventilation and illumination, further reducing running costs.

- Socio-Culture: Over the centuries, the Yoruba house has been continually refined in order to make it suitable to the people's lifestyle and culture. Therefore, it has important social advantages such as

- Suitability for traditional inheritance patterns,

- Affordable independence for groups with special needs such as young mothers or the aged,

- Consistent relationship of rooms to courtyard, courtyard to quarter and quarter to market square which allows for easy legibility and use of the urban environment.

- The Courtyard house form is also suitable for the privacy and security requirements of the Yoruba people, as well as social and cultural communication and continuity.

\section{BRIDGING THE CHASM BETWEEN THE OLD AND THE NEW}

Proposing a return to traditional ways of living and building is neither responsible nor desirable (Harries, 1992); however, achieving environmental suitability and encouraging cultural continuity is imperative. Aradeon (1981) gives the example of the combination of living and dining spaces in modern Yoruba architecture, which leads to embarrassment in the event of a visitor during meals. The problem of spatial layouts not reflecting environ- mental conditions in terms of relationships between open /semi-open and closed spaces observed in modern houses in the Mediterranean (Dincyurek et al, 2007) can also be seen in Yoruba land.

A proper understanding of the characteristics and advantages of the traditional Yoruba house as well as the social practices of the people is bound to yield more appropriate contemporary designs. Design professionals must consider the cultural norms, the traditional activities taking place within the spaces and their symbolic importance during planning and design (Rapoport, 1970). The bias against traditional building practices must be eradicated and the stigma of 'primitiveness' removed. This may be achieved by educating the people and raising their awareness about the benefits of natural materials for a sustainable built environment.

Uduku et al (2004) insist that the vestiges of tradition still observable in the south of Nigeria should be developed to instigate integration of old and new. These should include physical, aesthetic and theoretical reinterpretations of urban and house design. Modern realities such as internal conveniences, furniture, plumbing, space sizes, privacy and security should be reconciled with the lifestyle, economic, ecological and socio-cultural benefits of traditional Yoruba architecture.

Having already mentioned the physical advantages of the Yoruba house, which are common to similar dwellings utilizing natural materials, the issues of spatial quality, concepts and symbolism, and meaning and perception in Yoruba architecture will be briefly addressed.

Spatial Quality: Traditional Yoruba houses were rich in spatial quality. The modulated base and overhead planes and distinct entry experience at the border of each of the three zones added to this perception. This was achieved by the use of thresholds, differences in floor levels and ceilings to alter the scale of the space. However, modern examples of the traditional houses are omitting these importance spatial definitions which should be incorporated from the traditional in order to preserve spatial quality.

Social Spaces: Courtyards and halls are either being totally omitted or reduced in size as they lose their functions in modern houses. The introduction of such appliances as fans and electric cookers has enabled most of life to be carried out within the sleeping rooms, negating the need for halls or courtyards among non-related house 


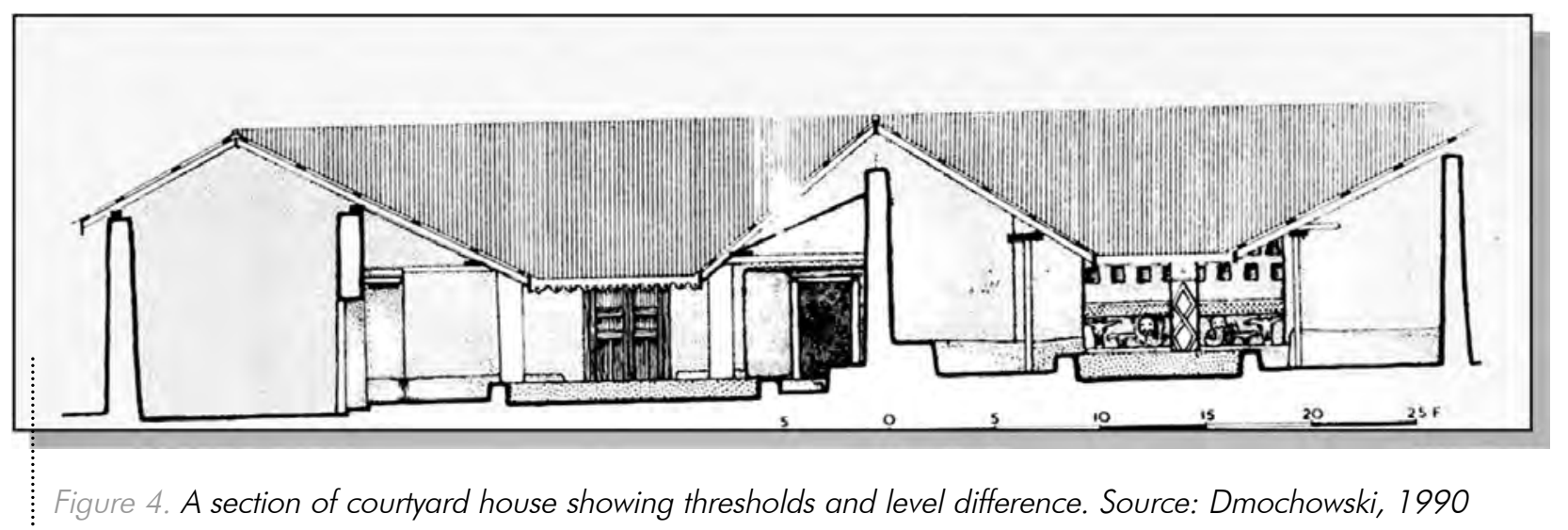

mates. The hall has, in many cases, been reduced to a mere access corridor. In the urban scale as well, social spaces are being lost in many towns. Squares and gathering places have mostly been built over, and the importance of communal entertainment and ceremonies is slowly being reduced. Changes in the system of government have relieved the kings and palaces of their hierarchical importance, and the introduction of supermarkets has diminished the social function of the market square. These developments are irreversible, and an expected outcome of democracy and globalization. However, the void left by the loss of such places must be consciously filled by contemporary social spaces like plazas, open markets for agricultural produce, parks, neighbourhood playgrounds, town halls etc.

Concepts and Symbolism: Symbolism is often considered to be concerned only with religious or sacred buildings (Rapoport, 1970), however need not be so. The purpose of signs and symbols include passing information and 'putting man in touch with the idea of a good place' i.e. an ideal space. The declining use of symbolism in architecture is partially as a result of a lack of shared symbolism in contemporary urban areas. Populations have become greatly mixed due to migrations, interracial mingling and availability of other cultures via mass media. Design practitioners have thus abandoned the use of symbolism altogether.

In Yoruba architecture, the significant choice of house form means that the dwelling itself functions as a symbol reminding people how to behave. It fits perfectly into the belief and value system of the society. Among the Yoruba, as in other developing countries where culture and tradition are still strong, it would be beneficial to identify what shared symbolism still exists in the built environment. This would assist designers in creating richer and more meaningful architecture. Furthermore, use of the built environment could be enhanced by a consistent set of symbols and signs, thereby avoiding the schism between symbolism and perception created when buildings do not 'look like what they are' (Rapoport, 1970).

Meaning and Perception: The meaning attached by users to their homes is proportional to the control they possess over their environment. Day et al (2003) assert that one's relationship to a space alter as soon as one is at liberty to do something about it. Finished products handed to users by modern architecture send the message that they are unimportant, alienating them in their own homes.

In Yoruba society, although people built their houses communally in antiquity, a professional building body with defined wages subsequently developed (Osasona, 2005). The home owner, however, still exerted enough control over the arrangement of the dwelling, thus retaining a sense of ownership, identity and belonging. The following arrangements assisted the Yoruba people in ascribing meaning to the built environment, and can be revived in modern architecture to create more significant places.

Participation in the Design Process: The home owner was responsible for the choice of house form, number of rooms, site, etc. The traditional family often contributed to the construction process in form of some ornamentation or thatching of the house. The contemporary gap between designer and user should be minimized and the user's input considered and incorporated in the design process.

Flexibility in Layout: This was achieved in two ways: multi-functionality of spaces and ease of transformation of the house form. Rooms could be 
added easily as needed by extending or filling in internal and external open spaces. Traditional furniture was seldom fixed, and spaces could assume functions as required. Modern designs should allow more flexibility in their function and arrangement. Furthermore, they should consider future changes in function, size, user profile etc.

Maintenance: Due to the use of earth and vegetable matter as construction materials, regular maintenance was required. This was in the form of a thin mud-vegetation-manure plaster called 'eboto' applied to the wall surfaces, and replacement of the roof thatch. Many of the maintenance jobs required in modern houses are too specialized to be carried out by the users. Simplified construction systems and education of the inhabitants will allow them to care for their homes themselves, thereby reducing their running costs as well.

Some researchers, such as Yurekli et al (2007), divide 'meaning' in terms of housing into two axes, mental and physical, both further subdivided into social and personal, and shelter and economic meaning. Due to the extended family structure and high urbanization of the Yoruba, the physical meanings of 'house' are likely already low. However, the personal meaning of 'house' has been rising among the Yoruba, as the social meaning declines. This is due to a breakdown of the communal and extended family system and the fact that many non-relatives now cohabit. These changes in meaning have affected the physical characteristics of many traditional spaces as well as the psychological perception of the users to them. Vandalism and neglect are on the rise with a decrease in perceived responsibility for a dwelling that means nothing to the user.

\section{CONCLUSION}

A home is more than a house, and it fulfils a number of psychological, social and physical roles for the users (Priemus, 2007). However, it is imperative that more than mere function be considered in the creation of a dwelling. The human element, codified by traditional building techniques like the Yoruba's in such ideas as meaning, symbolism, perception, concept and spatial quality, must be duly considered and reintroduced into the design process. This is especially important in Third-World countries and in other areas where centuries of tra- dition and culture are a present part of the people's lifestyle and where a large proportion of dwellings are of a traditional or vernacular nature. If African architecture is to take its place in solving world housing shortages, the following measures must be implemented.

- A return to environmentally and ecologically suitable building materials such as earth, using more appropriate methods of construction;

- Involvement and participation of the clients in the design process;

- A conscious effort to enhance spatial quality by manipulation of planes and textures, which will require a revival in quality craftsmanship for which the Yoruba are known;

- Deliberate use and reinterpretation of Yoruba house forms such as the courtyard house, and appropriate facilities to make them relevant and attractive to modern users.

The influences of other cultures and design traditions may as well be beneficial if sensitively handled in the design process. A reasoned and conscious mix of foreign and indigenous cultural influences may be achieved if design students are well versed in, and do not look down on, their own architectural heritage. It is in this way that the Yoruba House may remain both a testament to its past and a viable and vital solution to the problems of the people's present and future.

\section{REFERENCES}

AHMED, K. (2003), Quest for Regionalist Architecture in Bangladesh, Open House International, Vol. 28 no 3, pp 5 14, London, The Urban International Press

AFOLABI OJO, G. J (1966) Yoruba Palaces; A Study of Afins in Yorubaland, University of London Press,

Ltd

ANDERSEN, J. E, ANDERSEN, J, TIPPLE, G. (2006) The Demise of Compound Houses - Consequences for the Low Income Population of Kumasi, Ghana, RICS Research Paper Series, Vol. 6, No 8

ARADEON, D (1981) Space and House Form: Teaching Cultural Significance to Nigerian Students Journal of Architectural Education Vol. 35, No 1

ASOJO, A. O. (2003) Traditional African Architecture and its Effect on Place-Making: Case Studies from

African and African American Communities, Session Four, Legacies of Urban Realms and Rural Communities. 
http://www.cr.nps.gov/crdi/conferences/AFR_127134_Asojo.pdf.

BABALOLA, R.O. (2001) Architectonic Interregnum, INTBAU (International Network for Traditional Building, Architecture and Urbanism) Vol. 1 No 14

BRAY, J. M. (1968) The craft Structure of a Traditional Yoruba Town, Transactions of the Institute of British Geographers, No 46 (Mar, 1969), pp $179-193$

DAY, C (2002) Spirit and Place; Healing or Environment, Healing Environment, Oxford, Architectural Press

DAY, C; PARNELL, R. (2003) Consensus Design; Socially Inclusive Process, Architectural Press, Elsevier

DAYARTNE, (2003) Earth Architecture for Contemporary Living; Prospects and New Initiatives, Open House International, Vol. 28 no 3, pp 23 - 33, London, The Urban International Press

DINCYUREK, O. TURKER O. O. (2007) Learning from traditional built environment of Cyprus: Reinterpretation of the contextual values, Building and Environment, Volume 42, Issue 9, September 2007, Pages 3384-3392

DMOCHOWSKI, Z. R. (1990) An Introduction to Nigerian Traditional Architecture, Vol. 2, Ethnographica Books

ELLEH, N. (1997) African Architecture; Evolution and Transformation, McGraw Hill

FILANI, K. (2003) Perception of forms and motifs in Yoruba art, Papers presented at Yoruba Festival 2003 Symposium, held at University of Ibadan, 4th February, 2003.

HARRIES, K. (1992) Context, Confrontation, Folly, Perspecta, Vol. 27, pp $7-19$

IDOWU, W (2005) Law, Morality and the African Cultural Heritage: The Jurisprudential Significance of the Ogboni Institution, Nordic Journal of African Studies 14, 175 - 192

LAWAL, B (2000) Orilonise: The Hermeneutics of the Head and Hairstyles among the Yoruba, Tribal Arts Vol. 7, No 2

McINTOSH, S. K; McINTOSH, R. J. (1986) Recent archaeological research and dates from West Africa, Journal of African History 27: 413-442

MEIR, I. A.; ROAF, S.C., (2006) The Future of the Vernacular; Towards New Methodologies for the Understanding and Optimization of the Performance of Vernacular Buildings in Asquith, L; Vellinga, M. ed. Vernacular Architecture in the 21 st Century; Theory, Education and Practice, London, Taylor and Francis Group
OKOYE, I.S. (2002) Architecture, History and the Debate on Identity in Ethiopia, Ghana, Nigeria and South Africa, The Journal of the Society of Architectural Historians, Vol. 61 No 3, p $381-396$

OLIVER, P. (2007) "Shelter and Society: Vernacular Architecture in its Cultural Concepts", General Studies Lectures; Engineering towards Development and Change, Faculty of technology, University of Addis Ababa

OSASONA, C.O. (2001) Traditional Building Forms and Techniques, liebu-Ode, Nigeria; with Particular Reference to Iwesi, a Village on the Outskirts of the Town, INTBAU (International Network for Traditional Building, Architecture and Urbanism),Vol. 1 No 18

OSASONA, C.O. (2005) Ornamentation in Yoruba Folk Architecture, Ibadan, Bookbuilders Editions Africa

PRIEMUS, H (2007) The Essentials of Social Housing, Keynote ENHR Conference Sustainable Urban Areas, Rotterdam, Delft University of Technology

RAPOPORT, A. (1970) Symbolism and Environmental design, International Journal of Symbology, Vol. 1 No 3, April 1970

SONAIYA, O. A. (2008) Evolution, Analysis and Future of the Traditional Yoruba House, M.Arch Thesis, Eastern Mediterranean University, Gazimagusa, TRNC

UDUKU, O; Zack-Williams, A. (2004) Africa beyond the PostColonial; Political and Social Identities, Ashgate Publishing

VLACH, J.M. (1984) The Brazilian House in Nigeria: The Emergence of a 20th Century Vernacular House Type, The Journal of American Folklore, Vol. 97 No 383, pp 3-23

VLACH, J. M. (1986) The Shotgun House, an African Architectural Legacy, in Upton, Dell; Vlach, J. M. (eds), Common Places: Readings in American Vernacular Architecture, Athens: University of Georgia, 1986

YUREKLI, I; INCEOGLU, A. (2007) Urbanization as a Parameter of Change for Meaning of Homes, Open House International, Vol.32 No 1, London, The Urban International Press
Authors' Addresses:
Olusola A. Sonaiya
shonaia.s@gmail.com
Dr. Ozgur Dincyurek
Eastern Mediterranean University, North Cyprus
ozgur.dincyurek@emu.edu.tr 
Reproduced with permission of the copyright owner. Further reproduction prohibited without permission. 